\title{
Gathering and Giving Information With Families
}

\author{
Juliann J. Woods, PhD, CCC-SLP; David P. Lindeman, PhD
}

\begin{abstract}
The exchange of information between family members and service providers is a central feature of early intervention services and is integral to the development of an individual family service plan. Early intervention professionals pressured by timelines and documentation requirements either may resort to a directive style of communication that is not matched to the interaction or learning style of the family members or may ask general interview questions that do not provide sufficient information for effective intervention planning. Neither approach offers the family members a clear depiction of their role on the team. A framework and 5 strategies that support a reciprocal process for providing and receiving information while promoting family members' understanding of intervention in their everyday routines and activities are described. These strategies, developed and tested in the field within 5 federally funded research, demonstration, and outreach training projects, offer tools for service providers to gather and give information cognizant of different adult learning preferences. Key words: information gathering, reciprocal exchange, routines
\end{abstract}

\begin{abstract}
A N ESSENTIAL PRACTICE for assessment and intervention in natural environments is the identification of the routines, activities, and events that occur regularly for children and families at home and in the community. Gathering information about where families go, what they do, when they do it, and how they engage in the tasks of everyday life is pivotal to the identification of authentic outcomes and the initiation of intervention that has the likelihood of making a difference (Bernheimer \& Keogh, 1995; Bernheimer \& Weismer, 2007; McWilliam \& Scott, 2001). However, service providers are
\end{abstract}

\author{
Autbor Affiliations: Department of \\ Communication Disorders, Florida State University, \\ Tallabassee (Dr Woods); and Life Span Institute/ \\ Parsons, University of Kansas, Parsons \\ (Dr Lindeman).
}

Support for the initial work and development of the manuscript was received in part from grants from the US Department of Education, Office of Special Education and Rebabilitation Services (nos. H324CO20091, H024D30033, H024BOO15, H024070O28, and H324R990O79).

Corresponding Autbor: Juliann J. Woods, PbD, CCC-SLP, Department of Communication Disorders, Florida State University, Tallahassee, Fl 32306 (Juliann. Woods@comm.fsu.edu). challenged on multiple levels to gather this information. First, they are seeking personal information about the intricate workings of a family while developing rapport and building a relationship. Second, this sensitive task is amplified as information is sought from the family members while they are learning about their child's special needs, the early intervention (EI) services and supports available, and the professionals and systems that provide them (Fialka, 2000). Furthermore, service providers have a legislated timeline to develop an individual family service plan (IFSP) with the family when the child qualifies for services and the family is interested. The requirement of gathering information and completing documentation within 45 days exerts pressure for teams to be efficient and may limit giving information to the family about the principles and practices of EI. Finally, different models of service delivery create different demands for communication among team members and families. For example, when evaluation and IFSP teams involve different professionals than the intervention team, sharing information in a thorough and timely manner is difficult.

Many EI programs provide staff development activities on "why" better practices are 
important and "what" the changes should be, but often do not offer adequate information on "how" to accomplish the recommended changes in practice (Campbell \& Halbert, 2002). The purpose of this article is to present a framework and describe 5 strategies that are efficient and effective methods to engage the family members initially and support their continued participation throughout the intervention process. The strategies described have been field tested in multiple EI programs (Lindeman \& Woods Cripe, 1997; McLean, Lindeman, \& Woods Cripe, 1994; Woods, 2008; Woods Cripe \& Lindeman, 2001, 2004) and promote a reciprocal approach to assessment, IFSP development, and intervention planning. A reciprocal approach gives families information (eg, the relevance of teaching and learning opportunities within daily routines, their child's abilities) while gathering information (eg, the family members' concerns and priorities, the child's interests, and the places and activities of their daily life available for teaching and learning).

\section{THE NEED FOR A RECIPROCAL PROCESS}

Most families have little, if any, knowledge of EI prior to the referral of their child. They have not experienced the principles of family-based, natural environments, team decision making, or care provider-implemented approaches (Sandall, Hemmeter, Smith, \& McLean, 2005). If a family has any experience with EI, it is likely to be with a medical, a clinical, or an educational model, with expectations for team members to diagnose and prescribe a treatment, do therapy, teach, or give homework. It is fair to assume that without the knowledge of what EI is, why and how it is to be delivered, early interventionists should anticipate that families will need support at varying levels and types to participate fully (Bruder, 2000; McWilliam \& Scott, 2001). To put it simply, families need to have a clear description of what the program entails and what their roles are so that they can participate.
Unfortunately, because of time constraints, service providers frequently begin the evaluation and the IFSP process with intake paperwork and eligibility determination, and then proceed with assessment for intervention planning. They gather information about the child's health and development, family concerns, and resources and supports available or needed. Often, families are expected to describe their typical day, prioritize outcomes for the IFSP process, and identify contexts to embed teaching opportunities in 1 meeting. The individualization that is the framework of EI services is lost (a) when marathon meetings are conducted, $(b)$ jargon such as "natural environments," "transdisciplinary teams," "primary service providers," or "family-centered services" is used frequently, and $(c)$ documentation requiring signatures is amassed. Families may be participating without adequate knowledge of the purpose of EI, what their roles and responsibilities are, and what evidence supports the effectiveness of an approach (Peterson, Luze, Eshbaugh, Jeon, \& Kantz, 2007).

In a reciprocal process, family members become acquainted with the concept of "natural environments" through examples provided and reflection on their own lives and interactions. They learn that it is not about the places where they spend time with their children, but, more importantly, the experiences and learning opportunities that occur with their child through daily communications and routines. They learn that they are active participants in their child's development. Family members generally do not reflect on all the concepts their child is (or could be) learning while drinking from a bottle or riding a tricycle. Even if well informed, they may not recognize how essential their parenting role isand how simply they can increase opportunities or complexity of responses of their child without interfering with their primary role of being a nurturing parent (Dunst, Hamby, Trivette, Raab, \& Bruder, 2000). Families benefit from information about how young children learn by doing and that the family members' role in the process will be to "keep 
doing," not doing more or changing radically everything they have done (Jung, 2003). Families gain confidence and understanding when the information is shared with specific examples that emphasize their accomplishments, not the deficits. Throughout the process from assessment to intervention, the need for the reciprocity exists and can be supported through the use of a reciprocal process.

\section{Building a framework for a reciprocal process}

The ecological context of everyday routines, activities, and settings (Bronfenbrenner, 1979) serves as an anchor for the transactional interplay between caregivers and the child where learning occurs (Sameroff \& Chandler, 1975). Service providers benefit from information shared by families that describes their valued routines and interactions when developing intervention plans (Bernheimer \& Weismer, 2007). To share this information, families need to understand the value of the information to the service providers and the intervention process (Edelman, 2004; Woods \& McCormick, 2002). Reciprocal and respectful communication strategies support the effectiveness of the information sharing while maintaining efficiency by incorporating the following principles:

Sharing information concurrent with gathering information: Sharing information with the family about what, how, and where children learn while gathering information about the family's specific daily routines, activities, and events provides a context to establish a reciprocal process that will facilitate family participation throughout intervention. For example, dad is distracting his 15-month-old daughter with a game of peek-a-boo while answering questions about the family's schedule of typical activities. The early interventionist takes notes for the IFSP about morning routines, childcare, family work schedules, and the child's favorite activities. She notes Jessica prefers peo- ple rather than her many toys. While dad continues the game, the interventionist comments to dad that he is already helping his daughter develop communication skills, the major concern expressed by the family, while playing peek-a-boo. First, when he alters the tone of his voice or the words he says just a little each time his daughter pulls his face toward her, he is gaining her attention. When he pauses and gives her a chance to respond, he is helping her learn to take turns in games and conversations, and when he laughs with her, he is encouraging her to enjoy social interaction with others. The interventionist used a "teachable moment" to illustrate to dad the process of addressing the priorities for his child in natural environments by moving from abstract words to more concrete and meaningful examples of "how" it will be done.

Recognize each child and family is unique: To develop a truly family-centered program, information specific to the child and family's natural environments, preferences, values, and priorities must be known. The family must identify the routines, activities, and settings for the intervention to ultimately be effective and valued by the family. Although daily routines appropriate for intervention may seem obvious, they are individual to the family members on the basis of their interests, beliefs, and their unique characteristics. Family members and service providers would likely agree that a common daily routine for children and families is meals and snacks. This activity appears to provide several opportunities dispersed throughout the day to engage in planned learning opportunities. What is identified as an excellent activity by the provider may not be preferred by the family. The parents may value mealtime as a time for relaxing and sharing or find it too busy to focus on 1 child. Furthermore, the child may not be motivated by mealtime. Activities of interest to the child are important because they provide built-in 
motivation for exploring and expanding on current skills (Dunst, 2001; Wolery, 2005). Although providers may have preferred and comfortable intervention routines and activities, they should not automatically become the contexts for the child and the family. The family members should identify what they like to do and when and where they will be comfortable addressing intervention. They are also the experts on the activities and routines of interest to their child.

Develop an individualized plan for gathering and giving information: Families need a context to share information about their family. The service provider's first priority must be to establish a relationship with the family that underscores the relevance of the family members' perspective regarding their child, their values and beliefs, their concerns, and the outcomes they hope to achieve. Historically, service providers have initiated EI by focusing on an evaluation of the child's strengths and needs (Stremel \& Campbell, 2007; Woods \& McCormick, 2002). With the shift in service delivery resulting from the revision of IDEA (Individuals with Disabilities Education Act) legislation around natural environments, service providers are looking to the family for information that can guide the evaluation/assessment process and establish the intervention priorities. Rather than choosing the most appropriate child assessment tools, service providers are identifying the strategies most appropriate to establish the role of the family within the evaluation and IFSP. Service providers must prepare to involve the family members in this process by considering many variables that may influence their responses including family history, culture, religious beliefs and values, education level, primary language, and learning style of the caregivers. Environmental factors also impact families' responses such as work and school schedules, transportation options, and the number of people living in the household.
The team must set the stage to include the family as partners in the evaluation and assessment, IFSP development, and, ultimately, the intervention process. Addressing the family's preference for time and location, participants, and roles in each component of the EI process enhances the partnership process. Gathering information about each family's unique qualities helps the team prepare to both gather and give information that will be meaningful and functional. Time spent upfront establishing the reciprocal relationship is important for the team's success in implementation throughout the program.

\section{FIVE STRATEGIES THAT FACILITATE A RECIPROCAL APPROACH}

Service providers can benefit from using a variety of strategies both for initial identification of family and child contexts and for ongoing program development. In addition to sharing information about the child's skills, families share their routines, activities, and settings with service providers in many ways, both obvious and incidental. Strategies that are discussed include inventories and questionnaires, conversations, community mapping, ecological or environmental scans, and informal problem-solving discussions. No single proper procedure exists to gather and monitor information about the child and family's preferred settings and routines, and service providers need multiple methods to be able to choose an option that will support initial and ongoing exchanges (Table 1).

\section{Moving the interview to a conversation}

Having conversations with caregivers is a commonly recommended strategy for gathering information (McWilliam, 2005; Wilson, Mott, \& Batman, 2004). However, it is also an important strategy for giving information, especially during initial contacts when the pressure is on to gather information. For some families, engaging in 2 -way conversations or asking and answering questions are comfortable and effective. They are willing to share details, appreciate their importance, are 
Table 1. Tools for gathering information

\begin{tabular}{|c|c|c|}
\hline Strategy & When to use & What to share \\
\hline Conversations & $\begin{array}{l}\text { Initial contacts } \\
\text { Updates throughout } \\
\text { intervention }\end{array}$ & $\begin{array}{l}\text { Benefits of learning in everyday opportunities, } \\
\text { child development knowledge, impact of } \\
\text { disability, importance of parent-child } \\
\text { interaction }\end{array}$ \\
\hline Questionnaires & $\begin{array}{l}\text { Initial contacts } \\
\text { Periodic updates }\end{array}$ & $\begin{array}{l}\text { Role of family on team, typical development, } \\
\text { information supports progress }\end{array}$ \\
\hline Mapping & $\begin{array}{l}\text { Intervention planning } \\
\text { Transitions }\end{array}$ & $\begin{array}{l}\text { Community activities and resources, skill } \\
\text { generalization, family activities }\end{array}$ \\
\hline Problem solving & Throughout & $\begin{array}{l}\text { Options for intervention strategies, } \\
\text { adaptations, identification of learning } \\
\text { opportunities, affirmation of caregiver } \\
\text { strengths }\end{array}$ \\
\hline Environmental scan & $\begin{array}{l}\text { Initial } \\
\text { Regularly }\end{array}$ & $\begin{array}{l}\text { Potential routines, activities, environmental } \\
\text { arrangement strategies, examples of } \\
\text { outcome integration into family interests }\end{array}$ \\
\hline
\end{tabular}

anxious for intervention services to begin, are not concerned about approval from the provider, or respond to a provider skilled in facilitating nonintrusive discussions (McWilliam \& Scott, 2001). Other parents are less comfortable talking with unfamiliar people, engaging in face-to-face discussions, or responding to a list of questions they consider intimidating or intrusive (Vacca \& Feinberg, 2000). Adding difficulty to the situation may be a provider new to the process who asks broad or leading questions such as "What would you list as your natural environments?" or "What would you like Jasmine to work on?" Questions such as these often result in nonanswers, such as "I don't know," or answers that are vague, lack detail, or appear defensive. The family member's cultural and educational background, view of professionals as partners, and current status of emotional or physical health are factors that can impact responsiveness to questions or comments from a service provider.

The information gathered in an interview or a conversation will not only vary by the method employed but also be related to the variability of the family's lives (Bernheimer \& Keogh, 1995; Bernheimer \& Weismer, 2007).
When asked about their typical day, some families easily identify a list of activities and events that occur such as spending time with the toddler during snacks, diapering, playtimes, afterschool sport events for siblings, dinner with the family, and bedtime. Others focus only on specific activities related to the care of their child such as doctor's or therapy appointments, physical exercises, or medical procedures such as breathing treatments. Still other families laugh and respond that a typical day does not exist. They just go with the flow.

Closed-ended questions such as those on the intake or cover pages of the IFSP are often asked when family responses are vague or the service provider is in a hurry. However, they do not set the stage for a reciprocal partnership. Instead, they appear to be a test for parents to find answers that will assist them in receiving services and supports. It is important that caregivers understand "why" you are asking questions about their day. Explaining why knowledge of routines and activities is important is a priority for "giving" information and a logical initial step. Closed or checklistformatted questions do not share information about the context to help the caregiver see the value of sharing information. Identifying 
activities and routines with families could begin with conversation starters such as these that share important context (Fig 1) or descriptions such as:

1. We would like to learn more about your child's favorite activities and your family's daily routines because these are times when children learn and parents teach naturally such as playing peek-aboo games or while driving to grandma's house. By sharing information about a typical day, you are identifying opportunities when interactions that occur could be used to support your child's learning. Let us begin with you sharing the times during the day when you and your child are together. As the caregiver identifies various activities or routines, the interventionist expands on the information by describing the skills the child could be learning in each.

2. When a caregiver appears to be reluctant to respond to open-ended questions, offer friendly but more specific questions that focus the parent on child- or familypreferred activities, "I noticed you were in the yard with Kayla pulling the wagon when I drove up, does she enjoy wagon rides? What other play or outside activities do you both enjoy?" After getting some additional routines and activities that the child enjoys, the interventionist might share information about the value of building on the child's interests to enhance motivation and participation (Dunst, 2001).

3. Ask about specific routines that have a high probability of occurring such as dressing, watching TV, car travel, preparing/eating meals, household chores, bath, nap/bedtime stories, or "just hanging out" as a method for encouraging a more reserved caregiver to join into the process. Questions on the ease or the difficulty of specific routines will yield information beneficial to establishing initial priorities. Giving information about how teaching in the common chores of everyday life increases the functionality and meaningfulness of the skills being practiced and builds the caregiver's knowledge of how "intervention" occurs throughout the day without scheduling extra time and using special materials.

Explaining why information is important reduces the caregiver's concern and sets the stage for his or her participation. It is not enough to ask the right questions; they must be asked in a manner that encourages, rather than discourages, the family. Equally important is the ecology of the response. Is the caregiver responding with child-focused information or does it include all the family members? Do the activities illustrate the roles of informal supports and community? Does the response appear to be a daily schedule with a sequence of activities accompanied by times of the day (eg, We get up at 7:30 AM) or is it loosely defined to match the moment? It is important for service providers to remind themselves frequently that routines should not be equated with schedules. Routines occur for all children, but the schedule of when they occur will vary greatly. Knowledge of this differentiation between routines and schedules is instrumental for successfully gathering information from caregivers without appearing judgmental or biased. This can be even more valuable when explained to the caregiver who described a tightly scheduled day.

The child and family's day extends beyond the activities that occur at home (Bronfenbrenner, 1979). To gain a more complete picture of the family that will support the family's participation in the broader community, service providers could discuss:

1. activities or appointments (eg, doctor's appointments, workout) that occur on a regular basis (eg, once a week, every few days);

2. regular evening activities (eg, Wednesday night church, sibling involved in Girl Scouts);

3. recreational, seasonal, or spontaneous events (eg, sports, movies, camping);

4. family or friend socialization or celebrations (eg, family dinners, birthdays); and 
Family-guided Approaches to Collaborative Early intervention Training and Services

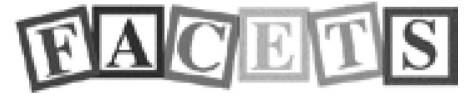 \\ Identifying Family Activities and Routines Conversation Starters}

Consider using some of these comments or questions to open a dialogue about the child's and family's activities, environments, and routines.

* We'd like to learn about some of your child's daily routines and activities for teaching and learning. By sharing your daily activities and routines, you are identifying potential times and places for your child's intervention.

* Tell me about your day. What are the routines/activities or places that you go that most often occur for you and your child?

* What types of things happen on most:
Mornings?
Afternoons?
Nights?
Weekends?

* Life with children usually makes us be pretty flexible. Can you give me some ideas about what usually happens before or after___ (Use some event the care provider mentions_ "One Life to Live." Systematically identify events, and then proceed.)

* If the careprovider is having difficulty identifying activities or routines, ask some specific questions about some of the following: dressing, breakfast, watching TV, car travel, preparing meals, household chores, nap, lunch and evening meals, yard work, bath, bedtime stories, or hanging out.

Possible follow-up questions to consider:

* Are there any activities or places that you go (eg, shopping, doctor's appointments) that occur on a less than regular basis (eg, once a week, every few days)?

* Are there other events that occur fairly regularly or during the weekend (eg, sport events for siblings)?

* Who are the important people who participate in your child's life? Who are helpful in your child's care, and who may also have activities and routines for teaching and learning (eg, grandparents, big brother, neighbor, friend)?

* What routines/activities does (child's name) enjoy doing?

- What makes this routine(s) enjoyable to

- What does usually do during the routine/activity?

- What do you (or the other care providers) do during the routine/activity?

- How long does it take?

* Are there opportunities for your child to interact with other children?

- How many other children participate in this routine/activity?

* What routine/activity(s) does not like?

- What makes this routine/activity difficult or uncomfortable for

- What does usually do during the routine/activity?

* What are your (family's) expectations of the children during the routine/activity?

- What do you do during the routine/activity?

- How do you let the child know what is expected in this routine/activity?

* Are there better times for you during the day or locations that are more comfortable for intervention routines?

\section{SUMMARY INFORMATION}

Potential outcomes

Care provider \& child routines

What to do

Who

Which Routine

Good times \& places

When Where

Figure 1. Conversation starters. FACETS is a joint project of Kansas University Affiliated Program and Florida State University. 
5. opportunities for the child to interact with peers (eg, church nursery, childcare, library story hours, play groups). Explaining how other family, friends, and activities enhance the child's learning logically follows identification of routines and activities within the community.

\section{Questionnaires and checklists: Making paper talk}

Another familiar strategy is the use of a questionnaire or a checklist that requests the family members to self-identify or describe their child's strengths, routines, activities, and settings. While certainly time- and costefficient, it can also be educational by offering possible categories of opportunities to families unfamiliar with the process. Ideas listed about family recreation, household chores, children's school activities, or errands serve as examples. These written documents may be commercially available (eg, Ages and Stages Questionnaire, parent-completed child monitoring system; Bricker \& Squires, 1999), developed by the service provider (eg, Getting to Know Your Child; Fig 2), or a component of the actual IFSP document (eg, specific sections or pages to document family members' information about their natural environments).

There are certain advantages to this strategy. Documents are frequently completed in the home or at the childcare center, the child's natural environments, making the setting conducive to accurate and thoughtful responses. The written format allows multiple caregivers to provide input and identify routines and activities. Family members can reflect on their responses for a few days and not feel the need for a quick response. The family may also choose to complete the form with a service provider, using the document as a guide to a conversation. There are also disadvantages to the use of questionnaires and checklists. They can be ignored, lost, or completed without attention to detail. Paper-and-pencil tasks may limit the depth or the breadth of the family response to the options or the space provided on the form. They are not interac- tive. Opportunities for follow-up or clarification may not be available or, at best, may be delayed until the service provider reviews the information. It is often difficult to establish the significance or the emotionality of the response from the written answer (Sexton, Snyder, Rheams, Barron-Sharp, \& Perez, 1991). Literacy levels must be considered. The service provider must carefully reflect on the appropriateness of paper-and-pencil tasks for each family. For the family to "get" information from the checklist, the interventionist should engage in a follow-up conversation with the parent that emphasizes the family members' role on the team as their child's expert and how the family information is used to support the other team members' practice (Woods \& McCormick, 2002).

\section{Community mapping: Pictures tell 1000 words}

Another format for gathering information about the child and the family, while sharing information about the purpose and process of EI, is a "mapping" strategy. Tools demonstrated in the work of Falvey, Forest, Pearpoint, and Rosenberg (1997) that can be used to help families identify their dreams and goals for their child in a long-range life plan are useful for the development of perspective and a plan for the immediate day-to-day program. An innovative use of this technique for EI is community mapping, a process in which a family identifies the natural learning opportunities that are occurring and offers information about inclusion opportunities available within their neighborhood (Dunst, Herter, Shields, \& Bennis, 2001). This strategy is very useful to introduce community activities or expand opportunities for the child and the family to engage in meaningful teaching and learning opportunities. This mapping provides concrete information and display of the current environments and illustrates possible options for the family. Giving families ideas for community resources within their defined community builds their independence. The strategy is especially useful when discussing potential locations/activities within the community to provide additional 


\section{Getting to Know Your Child}

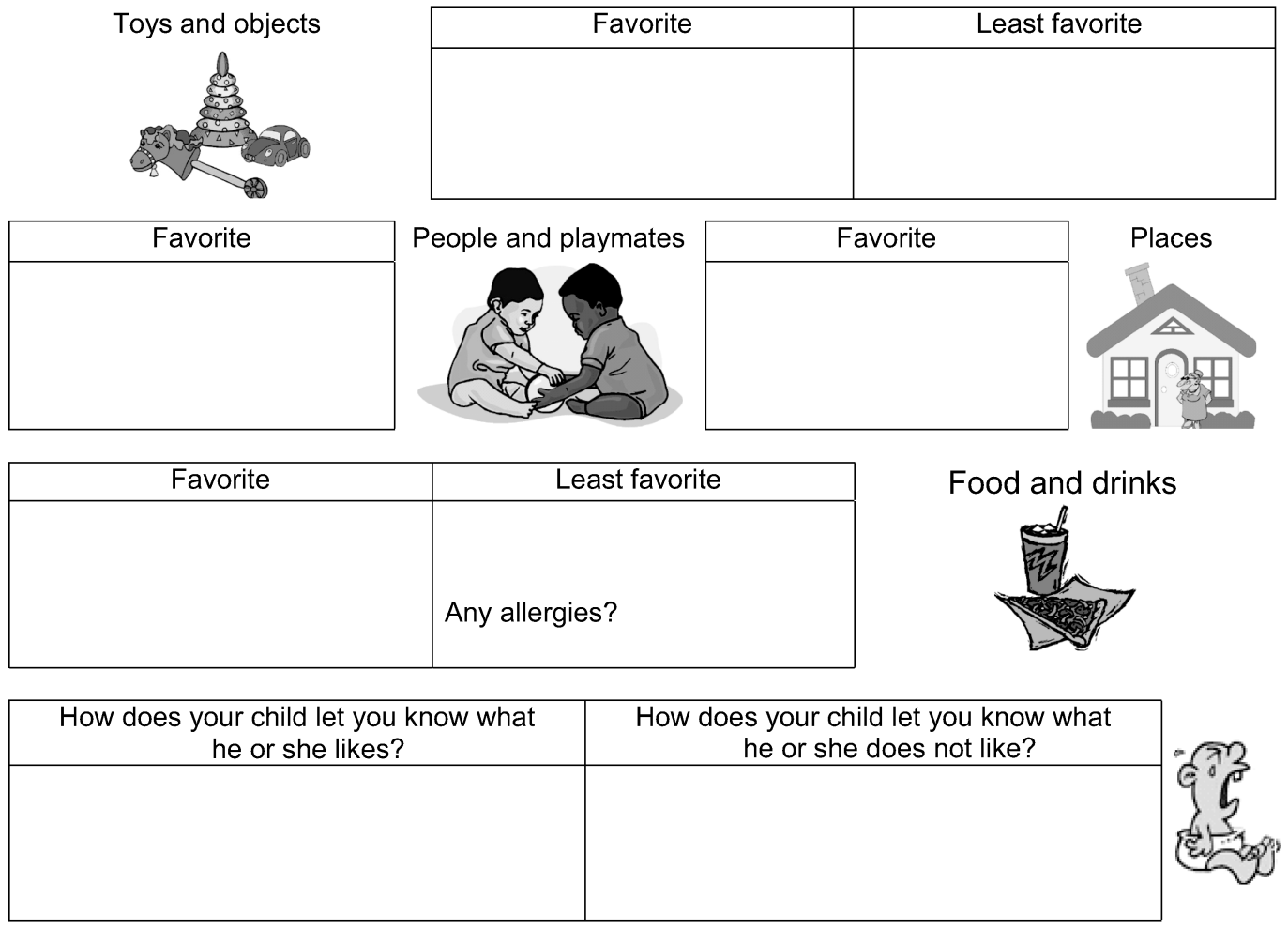

How does your child assist/participate in the following daily routines?

\begin{tabular}{|c|c|}
\hline Feeding & Dressing \\
\hline & Bathing \\
\hline
\end{tabular}

Figure 2. Getting to Know Your Child. Adapted from Noonan and McCormick (1993). Created for TaCTICS (Therapists for Collaborative Team Members for Infant/Toddler Community Services) at http://tactics.fsu.edu.

teaching and learning opportunities for identified outcomes.

\section{Problem-solving discussions: Working together}

While information important for the IFSP may be readily provided through previously identified strategies for most families, results may be superficial or lacking with others. Problem-solving simulations or discussions about "What do you do when?" can be used to identify intervention contexts and supports. The interventionist suggests a situation that could potentially occur for any family and asks the caregiver to describe what he or she might do (eg, your child has a doctor's appointment 
and your car is broken down or Joey is cranky and none of the usual toys or activities seem to be working). Problems such as these can be organized to identify informal or formal supports such as neighbors, family members, or agencies the family accesses during specific situations. Other situations might focus on more common day-to-day needs such as "What do you do when your baby won't take his bottle or has been crying or fussing for several hours?" Describing solutions to common problems provides information about the strategies the family uses, the resources and supports available, and other possible partners in the intervention process. This strategy also provides an opportunity for the family members and the service providers to initiate activities where joint problem solving is a comfortable process for working together.

Seeking information on what is not happening, where the family is not going, or how an activity is not working is another opportunity for problem solving with the family. The initial discussion may be in response to a direct question, "What routines or activities are difficult for you and your family?" or a statement shared in frustration to a team member, "We'd go to the park more often if the car ride wasn't such a horror." It may be an observation made incidentally during a home visit such as when dad struggles mightily to keep his toddler out of the dog food while the dog eats. While watching the interaction, the "light bulb" goes off for the service provider that problem solving some other environmental arrangements for the dog, its meals, and the toddler would be useful. Joint problem solving requires the service provider to listen to and observe the caregivers as they discuss and demonstrate concerns and problems they are having. Problem-solving simulations during the initial contacts set the stage for the ongoing use of the technique within the intervention process.

\section{Environmental scans: Making the most of life}

Service providers are trained to be good observers of child behaviors. Observations can enhance the identification of routines and activities by observing the environment where the child lives, learns, and plays. Service providers should look for familiar and preferred materials, as well as some uncommon or novel things that are present. Noticing potential activities and routines can become second nature after some practice. If music is playing, the interventionist could suggest it as an opportunity to the caregiver and problem solve with him or her on how to incorporate intervention such as a singing or a dancing routine between the child and the caregiver. Cardboard boxes in the kitchen may signify a new purchase for the family and result in a couple of great containers to use as pretend cars in the family room or the backyard. Scrapbooking materials on the dining room table could be the stimulus for the development of a photo book specific to the child's communication targets, thereby resulting in the development of 2 new routines-scrapbooking with the toddler and storytelling with the resultant scrapbook. Looking around the environment should not be mistaken for "being nosey." The ability to see the possibilities for intervention within everyday activities and settings necessitates familiarity with the child and family opportunities. Scans often identify new ideas to discuss with the family for expanding opportunities for teaching and learning.

Service providers can engage the caregiver in a scan of the child and family environment, looking for opportunities by discussing what "could be" and waiting for the family to decide what is preferred or is realistic. As the provider is greeted upon arrival, a "greeting" routine could be illustrated. A mirror by the front door could provide an opportunity for a game of peek-a-boo to extend the greeting. As the service provider and the caregiver determine what to do during a visit, discussion can focus on different locations and activities where the child could practice specific intervention outcomes. Furniture in the family room may be conducive to supported sitting because the corner of the couch is secure or the pillows from the chair provide a soft cushion if tipping over occurs. The 
family photos in the hallway could be a frequent opportunity for labeling familiar names without the added step of finding the photo book in the toy box. The location and the height of the garbage could make it a perfect discovery for practicing release of objects in defined spaces. Chasing the family cat could be a reason to crawl on hands and knees. Systematically scanning the environment with the intention of maximizing opportunities for practice that already exist for the child and the family decreases the amount of disruption to the family's life, and, more importantly, allows the family members to see all the natural learning opportunities that exist for themwithout adding more to their lives. Promoting the caregivers' active participation in the scanning process and problem solving with them about possibilities for embedding intervention increases their competence at initiating novel activities or adapting familiar ones.

The ability to gather information from parents and give it back within a context that illustrates recommended practices in EI necessitates a breadth of skills in communicating and processing information with adults that many EI service providers have not had the opportunity to learn and refine. Furthermore, it may be perceived as inefficient because it requires more time spent with parents during initial interactions. Intervention services are initiated when the paperwork is completed rather than when the family members feel competent and confident in their participation. With practice, service providers can accomplish both the paperwork and family participation outcomes. Positive outcomes of intervention will be related to the service provider's ability to simultaneously share information with the family on why daily routines and play are important for young children while gathering the required information for the development of the IFSP.

\section{APPLICATION OF THE STRATEGIES}

Development and refinement of the reciprocal processes described in this article have occurred in multiple settings. The 5 strategies are viewed as tools for the service provider to use separately or in combination, individualized for each family, and are interwoven rather than linear. For example, in the Southeast Kansas Regional Birth to Three Program, a welcome letter and the Getting to Know Your Child questionnaire (Fig 2) were mailed to each family after the referral phone call and prior to the first home visit. At the first meeting, it was used to support conversations about the child's interests, activities, and routines, emphasizing the importance of the parent's expertise and contributions. Specific questions, such as those listed in the conversation starters (Fig 1), were inserted to gain additional information or clarify content that the parent shared and that could be transferred to the intake and IFSP forms later. As in most service delivery programs, some families completed the document prior to the visit and others did not. Either way, families and service providers rated it as an effective tool for gathering and giving information in the program's annual evaluation. Having the form and the description of how it would be used prior to the initial visit, enhanced many families' feelings of competence during the 3-year demonstration project (Woods, 2008).

The use of problem-solving strategies during assessment and intervention was identified in focus group interviews and individual questionnaires as the families' preferred methods for learning about their child and how they could be involved in the teaching and learning processes (Kashinath, Woods, \& Goldstein, 2006; Woods, Kashinath, \& Goldstein, 2004). Using a team planning process, the unique learning styles of families were hypothesized and a sequence of assessment activities was developed with the families. Families shared information about their child and routines using a questionnaire (Fig 2), as well as conversations with the primary interventionist. Families actively participated in the curriculum-based assessment by interacting with their child in the routines they identified as interesting to the child and comfortable for the parent (Woods \& McCormick, 2002). Although the process was systematic, it was not 
always accomplished in a sequence. Service providers found that they used many of the strategies, interchanged them as appropriate in the assessment phase, and continued to use them throughout intervention. This emphasized the importance of flexible and empowering communication strategies to gather and give information to families as new priorities and interests developed, contrary to the more traditional step-by-step process utilized in IFSP development.

Problem solving as a strategy for assessment and intervention was incorporated into 2 studies and ranked highly by parents as effective for learning new intervention strategies and increasing confidence in using milieu teaching within daily routines (Kashinath et al., 2006; Woods et al., 2004). Problem solving enhances reciprocity and shared perspec- tives among participants in the gathering and giving information processes, resulting in better understanding of the context, an important step in the development of a trusting collaborative relationship and an effective intervention plan (Buysee \& Wesley, 2004).

Service providers with multiple strategies for gathering and giving information with families are better prepared to address the diverse learning styles and interests of families and caregivers. Following a strict protocol or documentation process may result in completion of the assessment process and compliance in specified timelines, but it may also limit the opportunities to gather important information and offer informational supports to the family. Efficiency without effectiveness is not a benefit to the program, providers, family members, or the child.

\section{REFERENCES}

Bernheimer, L., \& Keogh, B. (1995). Weaving interventions into the fabric of everyday life: An approach to family assessment. Topics in Early Childbood Special Education, 15, 415-433.

Bernheimer, L., \& Weismer, T. (2007). "Let me tell you what I do all day...": The family story at the center of intervention research and practice. Infants \& Young Children, 20(3), 192-201.

Bricker, D., \& Squires, J. (1999). Ages and Stages Questionnaires (2nd ed.). Baltimore: Paul H. Brookes.

Bronfenbrenner, U. (1979). The ecology of buman development: Experiments by nature and design. Cambridge, MA: Harvard University Press.

Bruder, M. B. (2000). Family-centered early intervention: Clarifying our values for the new millennium. Topics in Early Childhood Special Education, 20, 105115.

Buysee, V., \& Wesley, P. (2004). Consultation in early childhood settings. Baltimore: Paul H. Brookes.

Campbell, P. H., \& Halbert, J. (2002). Between research and practice: Provider perspectives about early intervention. Topics in Early Childhood Special Education, 22, 213-226.

Dunst, C. J. (2001). Participation of young children with disabilities in community learning activities. In M. J. Guralnick (Ed.), Early childbood inclusion: Focus on change (pp. 307-333). Baltimore: Paul H. Brookes.

Dunst, C. J., Hamby, D., Trivette, C. M., Raab, M., \& Bruder, M. B. (2000). Everyday family and community life and children's naturally occurring learning opportunities. Journal of Early Intervention, 23(3), 151164 .
Dunst, C. J., Herter, S., Shields, H., \& Bennis, L. (2001). Mapping community-based natural learning opportunities. Young Exceptional Children, 4(4), 16-24.

Edelman, L. (2004, July-September). A relationship-based approach to early intervention. Retrieved from http:// www.earlychildhoodconnections.org/files/relationship _based_approach.pdf. Originally published in $R e$ sources and Connections, 3(2).

Falvey, M. A., Forest, M., Pearpoint, J., \& Rosenberg, R. L. (1997). All my life's a circle. Toronto, Ontario, Canada: Inclusion Press.

Fialka, J. (2000). The dance of partnership: Why do my feet hurt? Young Exceptional Children, 4(2), 21-27.

Jung, L. A. (2003). More is better. Maximizing natural learning opportunities. Young Exceptional Children, 6(3), 21-27.

Kashinath, S., Woods, J., \& Goldstein, H. (2006). Enhancing generalized teaching strategy use in daily routines by parents of children with autism. Journal of Speech, Language, and Hearing Research, 49, 466-485.

Lindeman, D. P., \& Woods Cripe, J. J. (1997). Family-guided approaches to collaborative earlyintervention training and services (FACETS I Final Report). University of Kansas, Kansas University Affiliated Program at Parsons.

McLean, L. K., Lindeman, D. P., \& Woods Cripe, J. J. (1994). Southeast Kansas Regional Birth to Three Program (Final Report). University of Kansas, Kansas University Affiliated Program at Parsons.

McWilliam, R. A. (2005). Assessing the resource needs of families in the context of early intervention. In M. J. Guralnick (Ed.), A developmental systems approach 
to early intervention (pp. 215-234). Baltimore: Paul H. Brookes.

McWilliam, R. A., \& Scott, S. (2001). A support approach to early intervention: A three-part framework. Infants E Young Children, 13(4), 55-66.

Noonan, M. J., \& McCormick, L. (1993). Early intervention in natural environments: Metbods and procedures. Pacific Grove, CA: Brooks/Cole.

Peterson, C. A., Luze, G. J., Eshbaugh, E. M., Jeon, H. J., \& Kantz, K. R. (2007). Enhancing parent child interactions through home visiting: Promising practice or unfulfilled promise. Journal of Early Intervention, 29, 119-140.

Sameroff, A. J., \& Chandler, M. J. (1975). Reproductive risk and the continuum of caretaking casualty. In F. D. Horowitz, M. Hetherington, S. Scarr-Salapatek, \& G. Siegal (Eds.), Review of child development research (Vol. 4, pp. 187-244). Chicago: University of Chicago Press.

Sandall, S., Hemmeter, M. L., Smith, B. J., \& McLean, M. E. (2005). DEC recommended practices: A comprebensive guide for practical application in early intervention/early childbood special education. Longmont, CO: Sopris West.

Sexton, D., Snyder, P., Rheams, T., Barron-Sharp, B., \& Perez, J. (1991). Considerations in using written surveys to identify family strengths and needs during the IFSP process. Topics in Early Childbood Special Education, 11, 81-91.

Stremel, K., \& Campbell, P. H. (2007). Implementation of early intervention within natural environments. Early Childbood Services: An Interdisciplinary Journal of Effectiveness, 1(2), 83-105.

Vacca, J., \& Feinberg, E. (2000). Why can't families be more like us?: Henry Higgins confronts Eliza Dolittle in the world of early intervention. Infants \& Young Children, 13(1), 40-48.

Wilson, L. L., Mott, D. W., \& Batman, D. (2004). The assetbased context matrix: A tool for assessing children's learning opportunities and participation in natural environments. Topics in Early Childbood Special Education, 24, 110-120.

Wolery, M. (2005). DEC recommended practices in childfocused interventions. In S. Sandall, M. L. Hemmeter, B. J. Smith, \& M. E. McLean (Eds.), DEC recommended practices: A comprebensive guide for practical application in early intervention/early childhood special education (pp. 77-106). Longmont, CO: Sopris West.

Woods, J. (2008). Generalized effects of family guided early intervention routines (Final Report). Manuscript in progress, Florida State University, Tallahassee.

Woods, J., Kashinath, S., \& Goldstein, H. (2004). Effects of embedding caregiver implemented teaching strategies in daily routines on children's communication outcomes. Journal of Early Intervention, 26, 175193.

Woods, J., \& McCormick, K. (2002). Welcoming the family: Engaging family participation in assessment and evaluation. Young Exceptional Children, 6, 2-11.

Woods Cripe, J. J., \& Lindeman, D. P. (2001). Family-guided approaches to collaborative earlyintervention training and services (FACETS II Final Report). University of Kansas, Kansas University Affiliated Program at Parsons.

Woods Cripe, J., \& Lindeman, D. P. (2004). Therapists as collaborative team members for infant/toddler community services (Final Report). Tallahassee: Florida State University.

\section{Current articles- http://depts.washington.edu/isei/iyc/iyc_comments.html}

